This work was funded by a grant from the research support group of the Greater Glasgow Health Board.

1 Jarvis G, Hall S, Stamp S, Millar D, Johnson A. An assessment of urodynamic examination in incontinent women. Br $\mathcal{F}$ Obstet Gynaecol 1980;87:893-6.

2 Bates CP, Loose H, Stanton SL. The objective study of incontinence after repair operations. Surg Gynecol Obstet 1973;136:17-22.

3 Huskisson EC. Measurement of Pain. Lancet 1974;ii:1127-31.

4 Walter S, Vejlsgaard R. Diagnostic catheterisation and bacteruria in women with urinary incontinence. Br f Urol 1978;50:106-8.

5 Frewen WK. An objective assessment of the unstable bladder of psychosomatic origin. $\mathrm{Br} \mathcal{J}$ Urol 1978;50:246-9.

(Accepted 9 May 1986)

Department of Gynaecology, Stobhill General Hospital, Glasgow

D E PARKIN, MB, MRCOG, research registrar

J A DAVIS, MB, MRCOG, consultant gynaecologist

Correspondence to: Dr D E Parkin.

\section{A case of scurvy}

Sporadic cases of scurvy may continue to occur despite improved standards of living and food supply. Those at risk include people living alone and those with peculiar dietary habits, which are often taken to relieve symptoms. We report a case of scurvy in a young man whose diet was severely deficient in vitamin $\mathrm{C}$ as a result of exclusions devised to prevent alleged hypersensitivity to food. Current lay enthusiasm for dietary treatment of a great variety of symptoms may well lead to an increase in this type of deficiency. ${ }^{12}$

\section{Case report}

A 28 year old man, educationally below average, presented as an emergency with malaise, immobility, and a rash. Three years previously he had been referred for investigation of epilepsy, which had been diagnosed 14 years before. His parents, with whom he lived, had become convinced that his fits were due to food allergy, which they also blamed for his intermittent attacks of flatulence. Temporal lobe epilepsy had been diagnosed, and concurrent investigation for coeliac disease (including small intestinal biopsy) yielded negative results.

He was advised to eat normally, but his parents remained determined to prove

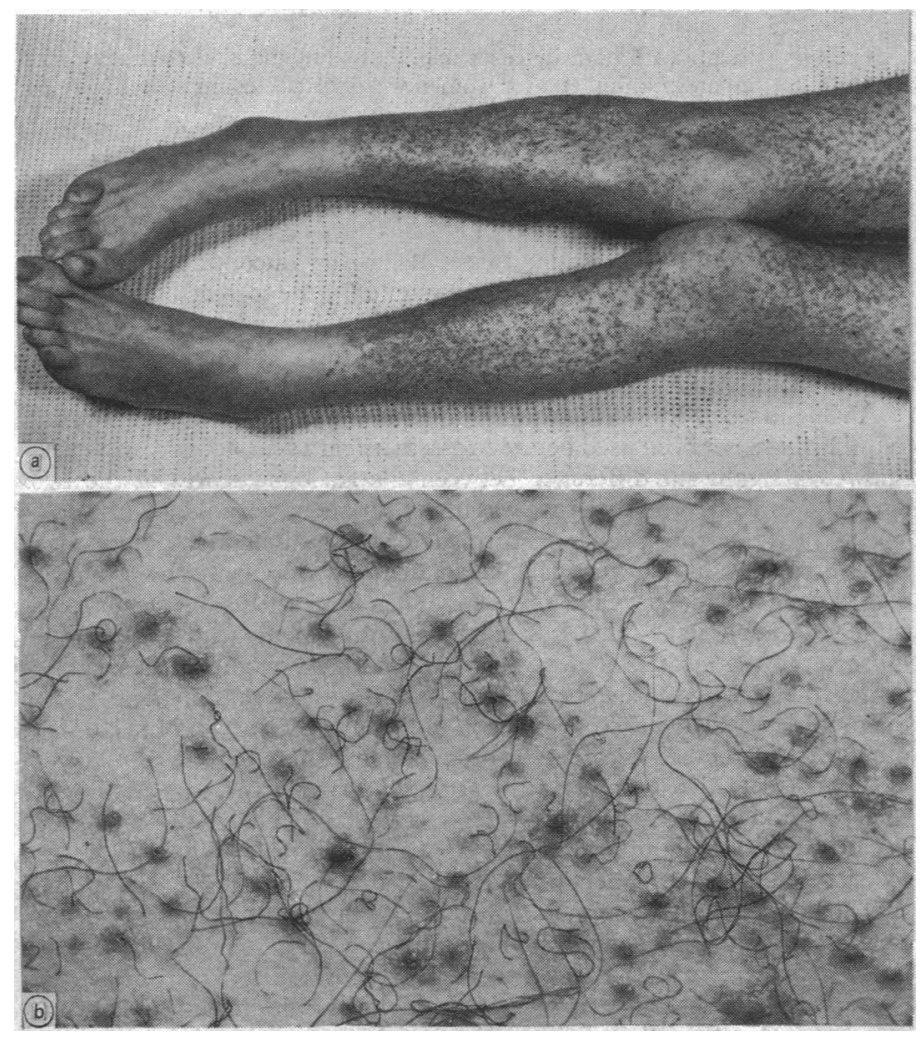

Pronounced petechial rash $(a)$ and corkscrew hairs $(b)$. that he suffered from food allergy. To this end he consulted many practitioners, each of whom added different advice and fresh exclusions to his dwindling diet. A few months before admission he attended an alternative medicine clinic, which excluded all potatoes, oranges, and lemons on the unsupported grounds of allergy. No advice seems to have been given about vitamin intake. His mother was strict with these exclusions, so that on admission his diet consisted of only eight foodstuffs: gluten free bread, rice cakes, vegetable margarine, apple juice, steamed white cod, brown rice, yeast pâté, and occasional portions of green vegetables. His daily intake with this diet was protein $62 \mathrm{~g}$, fat $66 \mathrm{~g}$, and carbohydrate $305 \mathrm{~g}(8 \cdot 8 \mathrm{MJ} ; 2095 \mathrm{kcal})$. His daily intake of vitamin C was $10.2 \mathrm{mg}$ (recommended daily intake $30 \mathrm{mg}^{3}$ ), of iron $13.4 \mathrm{mg}$, and of folate 7.7 $\mu \mathrm{g}$.

He gave a two month history of increasing fatigue, difficulty in walking, pallor, and a rash over his buttocks and legs, which in the days before his admission had become pronounced (figure) with painful swelling of both knees, ankles, and elbows. There had been one episode of haemoptysis but no overt gastrointestinal bleeding. On examination he was pale and thin and had a widespread petechial rash over both buttocks and lower abdomen, with tiny corkscrew hairs. Recent bleeding from the gums was visible, and fresh tender bruising was present behind the knees and ankles, indicating bleeding around these joints.

Investigation showed haemoglobin concentration $84 \mathrm{~g} / 1$, white cell count $5.1 \times 10^{\%} / 1$, mean corpuscular volume $83 \mathrm{fl}$, and serum $B_{12}$ concentration $153 \mathrm{ng} / 1$, leucocyte ascorbic acid concentrations were too low for accurate measurement. Other investigations, including chest $x$ ray examination, yielded normal results. He made a dramatic recovery, being able to walk within 48 hours after receiving oral vitamin $\mathrm{C}$. He subsequently took vitamin supplements and remained well.

\section{Comment}

Adult scurvy commonly presents with fatigue, weight loss, arthralgia, depression, and weakness. ${ }^{4}$ There is a tendency to bleed, with swollen, friable gums, loosening of the teeth, and perifollicular haemorrhages. Other features include associated anaemia and corkscrew hairs. Our patient's die was grossly deficient in vitamin $\mathrm{C}$ because of his parents' conviction that he had a food allergy. There is widespread interest in alternative medicine, in which dietary exclusions may feature. ${ }^{1}$ Our patient shows the harm that may come from this; as scurvy is uncommon, delay in diagnosis may occur. Indeed, patients with scurvy may die suddenly without warning from cardiac failure. ${ }^{5}$ Doctors therefore need to have a heightened index of suspicion for deficiencies when patients are following exclusion diets, for whatever reason.

1 May CD. Food sensitivity: facts and fallacies. Nutr Rev 1984;42:72-8.

2 Royal College of Physicians and British Nutrition Foundation. Food intolerance and food aversion. $f R$ Coll Physicians (Lond) 1984;18:83-123.

3 Committee on Medical Aspects of Food Policy. Recommended daily amounts of food, energy, and nutrients for groups of people in the UK. London: HMSO, 1979.

4 Reuler JB, Broudy VC, Cooney TG. Adult scurvy. JAMA 1985;253:805-7.

5 Sament S. Cardiac disorders in scurvy. N Engl 7 Med 1970;282:282-3.

(Accepted 19 May 1986)

\section{Queen Alexandra Hospital, Portsmouth}

M HUGHES, MB, BS, house physician

N CLARK, MB, BS, house physician

L FORBES, BSC, SRD, chief dietitian

D G COLIN-JONES, MD, FRCP, consultant physician

Correspondence to: Dr Colin-Jones.

\section{Diabetic renal disease: differences between Asian and white patients}

A recent survey by the World Health Organisation suggested that ethnic differences might result in differences in the prevalence of small vessel disease in diabetics. ${ }^{1}$ We undertook this study to determine whether the prevalence of diabetic nephropathy differed between Asian and white patients attending the Leicester diabetic clinic.

\section{Patients, methods, and results}

We studied 370 consecutive Asian and 368 consecutive white patients who had attended the diabetic clinic for at least one year (table). Patients were regarded as Asian if they originated from the Indian subcontinent (India, Pakistan, Bangladesh, and Sri Lanka). Proteinuria was considered to be present if Albustix testing of urine on at least two occasions at least six weeks apart yielded positive results, 24 hour protein excretion was $>0.5 \mathrm{~g}$, and there was no urinary tract infection or evidence of disease of the renal tract on intravenous pyelography. Retinopathy 
was assessed in each patient by two clinicians by ophthalmoscopic examination of the ocular fundi through fully dilated pupils. Statistical analysis was by the $\chi^{2}$ test. Proteinuria was found in $53(14 \%)$ of the Asian and $23(6 \%)$ of the white patients $(p<0.001)$. There was no difference in the sex distributions of patients with proteinuria. Proteinuria in the Asians tended to occur with diabetes of shorter duration $(<10$ years $)(p<0.01)$ and in the absence of clinical retinopathy $(p<0.001)$. No significant differences were noted in glycaemic control or the prevalence of hypertension between the two groups (table). Twenty five of the

Clinical details of patients studied

\begin{tabular}{|c|c|c|c|c|}
\hline & \multicolumn{2}{|c|}{ Asian } & \multicolumn{2}{|c|}{ White } \\
\hline No studied & & 370 & & 368 \\
\hline Men & 228 & & 223 & \\
\hline Women & 142 & & 145 & \\
\hline Mean (SD) age (years) & & $52(12)$ & & $58(15)$ \\
\hline Mean (SD) duration of diabetes (years) & & $8(3 \cdot 6)$ & & $12(4 \cdot 2)^{\star}$ \\
\hline No $(\%)$ treated with insulin & & $135(37)$ & & $258(70)^{\star}$ \\
\hline No $(\%)$ with proteinuria & & $53(14)$ & & $23(6)^{\star \star}$ \\
\hline Men & 32 & & 14 & \\
\hline Women & & & 9 & \\
\hline Without retinopathy & $25(47)$ & & $4(17)^{\star}$ & \\
\hline With hypertension $\geqslant 160 / 95 \mathrm{~mm} \mathrm{Hg}$ & $27(51)$ & & $14(62)$ & \\
\hline Mean (SD) glvcosylated haemoglobin (\%) & & $9 \cdot 5(2 \cdot 0)$ & & 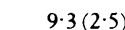 \\
\hline
\end{tabular}

${ }^{\star} \mathrm{p}<0.01,{ }^{\star \star} \mathrm{p}<0.001$.

228 Asian men had a serum creatinine concentration above normal $(>120 \mu \mathrm{mol} / \mathrm{l}$ $(>1.4 \mathrm{mg} / 100 \mathrm{ml}))$, compared with 11 of the 223 white men $(p=0.02)$. No such difference was found in the women.

\section{Comment}

Our results indicate that proteinuria is more common in Asian than white diabetics attending the diabetic clinic at Leicester. We believe that this is due to small vessel disease of diabetes as we excluded other causes of renal disease both clinically and radiologically. This difference in renal disease could not be accounted for by variation in glycaemic control or the prevalence of hypertension. Ethnic cultural factors may influence patterns of referral to hospital, but we do not believe that this occurs in Leicester and our view was substantiated by inquiries to general practitioners. Patients with specific diabetic complications are generally not discharged from the clinic, which therefore suggests that the observed difference in renal disease was real and not an artefact.

A larger proportion of Asian patients had proteinuria with diabetes mellitus of less than 10 years' duration and in the absence of clinical retinopathy. The shorter duration of diabetes may partly be because many of the Asians had non-insulin dependent diabetes mellitus, in which the timing of onset may be inexact. It is also possible that differences in immunogenetic influences in populations from different cultures determine the development of diabetic nephropathy, and this aspect requires further study.

Asian people in Leicester tend to come originally from the Gujarat region of India, having migrated through east Africa. Women are usually vegetarian, but men are not. ${ }^{2}$ Consumption of animal protein influences the speed of progression of renal disease, ${ }^{3}$ and this may explain the significantly higher serum creatinine concentration observed in the Asian men.

The higher prevalence of proteinuria in Asian diabetics in this hospital based study should be confirmed by epidemiological work based on the population at large. This is particularly important in view of the high prevalence of diabetes mellitus in Asians in the United Kingdom. ${ }^{45}$

1 Diabetes Drafting Group of the World Health Organisation Multinational Study of Vascular Disease in Diabetics. Prevalence of small vessel and large vessel disease in diabetic patients from 14 centres. Diabetologia 1985;28 (suppl):615-40.

2 Leicester City Council and Leicestershire County Council. Suroey of Leicester 1983. Leicester: Leicester City Council and Leicestershire County Council, 1983.

3 Williams AJ, Baker FE, Walls $J$. The effect of dietary protein quality in experimental renal disease. Proc Eur Dial Transplant Assoc 1985;22:921-6.

Proc Eur Dial Transplant Assoc 1985;22:921-6.
4 Mather HM, Keen H. The Southall diabetes survey: prevalence of known diabetes in Asians and Mather HM, Keen H. The Southall diaberes
Europeans. BrMed f 1985;291:1081-4. 5 Samanta A, Burden AC. Prevalence of non insulin dependent diabetes mellitus (NIDDM) in Asian
Indians. Clin Sci 1986;70 (suppl 13): 19 .

(Accepred 2 fune 1986)

Leicester General Hospital, Leicester LE5 4PW

A SAMANTA, MD, MRCP, Pfizer clinical research fellow

A C BURDEN, MD, MRCP, consultant physician

J FEEHALLY, MRCP, senior registrar (nephrology)

JWALLS, MB, FRCP, consultant nephrologist

Correspondence to: Dr Burden.

\section{Awareness and use of glucagon in diabetics treated with insulin}

Recent surveys have shown that $4 \%$ of deaths in diabetics under the age of 50 are caused by hypoglycaemia, ${ }^{1}$ and $4-10 \%$ of patients treated with insulin experience one or more severe episodes each year. ${ }^{23}$ Glucagon is an effective drug for such patients and can be given by a relative, friend, or medical attendant. There is little information available about the policies of diabetic clinics in prescribing this drug. We have therefore examined the frequency of hypoglycaemia and the awareness and use of glucagon and its effectiveness in preventing hospital attendance among routine clinic patients.

\section{Patients, methods, and results}

Five hundred and four consecutive diabetics treated with insulin routinely attending a clinic over two months were asked about their awareness of glucagon, whether it was kept at home and in date, if it had ever been given, and whether this had prevented hospital attendance. Patients were questioned about the frequency of mild, moderate, or severe hypoglycaemia (severe hypoglycaemia being defined as that aborted by parenteral treatment). They were also asked whether their general practitioner had been called and whether casualty attendance or hospital admission had been required because of hypoglycaemia. Glycosylated haemoglobin concentrations were measured by electrophoresis, the normal range being $5 \cdot 5-7 \cdot 9 \%$. Statistical analyses used were Wilcoxon's rank sum test, Spearman rank correlation coefficient, and $\chi^{2}$ test.

The table shows the clinical details of the patients. Of the 504 patients, 252 $(50 \%)$ had heard of glucagon and $155(30 \%)$ kept glucagon at home, of whom 114 $(23 \%)$ were certain it was in date. One hundred and eight patients had received

Clinical details of 504 consecutive diabetics treated with insulin. (Values are means $(S D))$

\begin{tabular}{lr}
\hline Sex $(\mathrm{M}: \mathrm{F})$ & $249: 255$ \\
Age (years) & $41 \cdot 0(16 \cdot 9)$ \\
Body weight (kg) & $68 \cdot 25(11 \cdot 4)$ \\
Duration of insulin treatment (years) & $14 \cdot 1(10 \cdot 3)$ \\
Daily insulin dose (units) & $52 \cdot 8(22 \cdot 5)$ \\
Number of clinic visits in past year & $4 \cdot 3(2 \cdot 7)$ \\
Total glycosylated haemoglobin concentration (\%) & $12.0 \quad(3 \cdot 8)$
\end{tabular}

glucagon at home at least once, of whom $92(85 \%)$ were convinced that casualty attendance or hospital admission had thus been prevented. Of 175 patients whose general practitioner had been called out in the past because of severe hypoglycaemia, 102 had heard of glucagon. Of 136 attending a casualty department for hypoglycaemia, 61 had heard of glucagon, and of 81 admitted because of hypoglycaemia, 49 had heard of glucagon. In the year before the study $67(13 \%)$ had experienced one or more episodes of severe hypoglycaemia, this being more common in younger patients $(\mathrm{p}<0.001)$, those with lower glycosylated haemoglobin concentrations $(p<0.001)$, those who visited the clinic more often $(p<0.001)$, those receiving a higher dose of insulin per kg body weight $(p<0.01)$, and those who kept glucagon at home $(\mathrm{p}<0 \cdot 0005)$.

\section{Comment}

Hypoglycaemia continues to be a hazard for diabetics, with $67(13 \%)$ of our patients treated with insulin experiencing one or more severe episodes in the year before the study. Such episodes occurred in younger patients with lower glycosylated haemoglobin concentrations, suggesting that patients with better glycaemic control are more at risk. If improved glycaemic control is the main goal of diabetic management then it is essential that patients and their relatives know how to cope with this problem.

Glucagon is an effective treatment for hypoglycaemia ${ }^{4}$ and this is confirmed by our finding that of 108 patients given glucagon at home or work, only 16 required subsequent hospital attendance. It is clearly a useful first line of defence given subcutaneously at home or work, while in general practice or at the hospital it can be given intramuscularly or intravenously with a quicker effect. ${ }^{5}$

Patients' knowledge of the use of glucagon still seems limited, with half of those interviewed unaware of its existence and only about a third keeping it at home. Those patients with more frequent episodes of severe hypoglycaemia, however, did keep glucagon at home, although, disappointingly, some patients who had been admitted to hospital because of hypoglycaemia before had not heard of glucagon.

In view of these findings and the possible saving in costs incurred when general practitioners are called out and in hospital attendances and admissions, we believe that all diabetics treated with insulin should have glucagon at hand, provided that a relative or friend is available and trained in administering it. 